\title{
O "ESPAÇO DE MORAR" NA ARQUITETURA MODERNA: REFLEXÕES A PARTIR DE QUATRO RESIDÊNCIAS DE IRATI - PR
}

\section{The "dwelling space" in modern architecture: reflections on four residential buildings in Irati - Paraná (Brazil)}

\author{
Gigliese Aparecida Mendes \\ Historiadora, mestranda em Gestão do Território pela UEPG \\ gigliesem@hotmail.com \\ Cicilian Luiza Löwen Sahr \\ Profa. dos Programas de Pós-Graduação em Geografia da UEPG e UFPR \\ cicilian@uol.com.br
}

Artigo recebido em 27/02/2012 e aceito para publicação em 17/04/2012

Resumo: $\quad$ Este artigo analisa o 'espaço de morar' influenciado pelo movimento modernista na cidade de Irati - PR, enfatizando seu aspecto espacial. A análise ocorre a partir de quatro residências unifamiliares construídas durante a década de 1950, projetadas por Eduardo Posfaldo, profissional local. Nestas são observados elementos arquitetônicos característicos do modernismo, como os pans de verr e pilotis. Valorizando-se as linhas retas, $o$ 'espaço de morar' é concebido de forma racionalista. A partir da análise destas habitações, foi constatado que estas ocupam um percentual relativamente pequeno (31\%) de seus lotes, o que permite inferir a importância das áreas verdes e jardins nesta modalidade de 'espaço de morar'. No interior das habitações, a ênfase em termos de área está nos espaços íntimos (28,5\%), seguidos dos espaços sociais (26\%). Um aspecto singular encontrado em Irati é o compartilhamento do 'espaço de morar' com o 'espaço profissional'.

Palavras-chave: Arquitetura modernista; espaço de morar; Eduardo Posfaldo; Irati - PR

\begin{abstract}
This article is an analysis on the transformations of the 'dwelling space' induced by the modernist movement in Irati - Paraná. It focuses on four residential buildings which have been constructed throughout the 1950s under the supervision of Eduardo Posfaldo, a local architect. Here, the characteristic architectural elements of modernism, like glass walls and pilotis, can be observed. Valorizing straight lines, the modern dwelling space has been conceived through rationalist forms. The analysis of these residential buildings shows that they are covering a relative small portion of their lots, a fact that is highlighting the importance of green areas and garden features in this type of dwelling space. Inside of the buildings, there is a strong emphasis on intimate spaces $(28,5 \%)$, followed by social spaces $(26 \%)$. A singularity of Irati is that dwelling space and professional space are shared.
\end{abstract}

Keywords: Modernist architecture; dwelling space, Eduardo Posfaldo; Irati - Paraná (Brazil) 
O "espaço de morar" na arquitetura moderna: reflexões a partir de quatro residências de Irati - PR

\section{INTRODUÇÃO}

Irati, cidade situada no centro-sul do Paraná, presenciou um desenvolvimento significativo em sua configuração urbana a partir da década de 1950. Nesta fase, o movimento da arquitetura modernista estava em seu auge no contexto brasileiro, mostrandose presente em várias regiões do país, primeiramente nas grandes cidades e, gradativamente, também nas cidades de médio e pequeno porte. É nesta fase, entre 1950 e 1970, que a cidade de Irati presencia mudanças nos estilos de construir, surgindo os primeiros projetos residenciais modernistas, os quais acarretaram uma intensa transformação nos 'espaços de moradia'.

Desta forma, o objetivo central deste artigo é analisar os 'espaços de morar' iratienses influenciados pelo movimento modernista. A análise se restringe a fase inicial desta influência, ou seja, a década de 1950, e enfatiza os aspectos espaciais internos das moradias e suas diferentes funções relacionadas ao morar. Para isso, foram reunidas plantas de quatro residências unifamiliares desenhadas por Eduardo Posfaldo, profissional local, detentor de forte influência modernista e responsável pela criação da maioria das residências modernistas de Irati. Tais plantas fazem parte do acervo do Departamento de Controle Interno de Documentos da Prefeitura Municipal da cidade. Os quatro exemplos de edificações se localizam no centro da cidade, sendo três de médio porte, ou seja, com metragem quadrada inferior a 220 , e uma de grande porte, ou seja, com metragem quadrada superior a 350 .

As técnicas de leituras das edificações utilizadas foram pautadas na metodologia empregada por Zevi (1996) em sua obra intitulada Saber ver a Arquitetura. O autor declara que o espaço interior é o que dá sentido à arquitetura, salientando três aspectos de análise: o econômico-social, o técnico e o espacial. Optou-se aqui por priorizar a interpretação espacial, pois se entende que esta não se trata de uma visão específica, mas sim de uma visão que engloba todas as demais.

$\mathrm{O}$ artigo busca assim, refletir a complexidade escalar do fenômeno em estudo, articulando a escala global, a do ideário modernista, o contexto nacional $\mathrm{e}$ as condições locais, representadas pelas criações de Posfaldo em Irati. Aprofunda-se nestas a análise a partir da categoria 'espaço de morar'.

Considerando-se que o 'interior' é o protagonista da arquitetura, o espaço arquitetônico é analisado enquanto 'espaço de morar'. Tal análise busca respaldo na metodologia elaborada por Veríssimo e Bittar. Para estes autores, a casa transcende as simples formas geométricas, "uma realidade visível e tangível" (1999, p. 9), no momento em que o 'morar' resulta de um processo criativo, conduzido pelas necessidades sociais e culturais do homem. Assim, busca-se captar a integração entre homem e casa, entendendo que esta passa de um conjunto de volumes, planos, linhas retas e curvas, a um espaço a ser vivido pelo homem, adquirindo valores humanos.

\section{ARQUITETURA MODERNA: OLHAR GLOBAL ADAPTADO AS CONDIÇÕES LOCAIS}

Ao contrário do que muitos estudiosos afirmam, a globalidade, ou como é costumeiramente chamada, a globalização, não é um processo recente. A globalidade, nada mais é que a modernidade em escala global. Robertson (2000), em sua obra Globalização. Teoria Social e Cultura Global, defende que o processo de globalização é tão antigo quanto a emergência das chamadas religiões mundiais, datando aproximadamente dois mil anos. $\mathrm{O}$ fato é que o termo foi debatido longamente em discussões acerca da modernização e da pós-modernidade nas décadas de 1950 e 1960. Tal discussão, todavia, só veio a tomar corpo nas décadas seguintes, assumindo-a como um processo massificador.

A leitura que Santos (2009) faz acerca da globalização e da dialética existente entre a escala global e local não pode ser esquecida. $\mathrm{O}$ autor, ao citar Serres, "Nossa relação com o mundo mudou. Antes, era local-local; agora é local-global" (apud SANTOS, 2009, p. 313), mostra que o filósofo foi bem sucedido no argumento ao pensar na globalização como um processo que organiza uma nova relação com o mundo, marcada pela fluidez, pela velocidade da informação e das inovações.

Nesta conjuntura, segundo Santos (2009), cada lugar é o mundo e todos os lugares são virtualmente mundiais. Ao passo que os mais distantes pontos do globo terrestre se aproximam através desse processo 
massificador, cada lugar torna-se diferente dos demais. $\mathrm{O}$ autor afirma que a localidade se opõe à globalidade, mas ao mesmo tempo se confunde com ela. Assim, globalidade e individualidade andam juntas.

Robertson (2000, p. 144) afirma que o universalismo não pode ser visto como algo relacionado a princípios aplicados a todos, e o particularismo se referindo apenas ao que é 'local'. "Os dois se entrelaçaram como parte de um nexo global". O autor relata que ambos se uniram, dando origem à particularização do universalismo, o qual envolve a idéia do universal com concretude globalhumana e a universalização do particularismo, em que não existe limite para a particularidade, a singularidade e a diferença. Assim, segundo ele, a globalização acaba sendo constituída "de processos interpenetrantes de socialização, individualização, consolidação do sistema internacional de sociedades e ainda como a concretização do senso de humanidade" (2000, p. 147).

Ao se pensar na globalização da cultura, podese "observar a circulação dos fluxos culturais a nível mundial ou como eles são recebidos a nível local" (WARNIER, 2000, p. 143). A partir de um ponto de vista local, pode-se analisar a recepção localizada da cultura, e não a emissão da cultura globalizada. Tal situação, segundo o autor, é muito mais complexa e contrastante, se comparada com a situação globalizada. Desta forma, pensar a arquitetura modernista a partir de Irati, e sobretudo, das edificações de Posfaldo, é pensar a recepção localizada de uma cultura globalizada.

Hall (2006, p. 67-68) considera o termo 'globalização' como o processo que "atravessa fronteiras nacionais, integrando e conectando comunidades e organizações em novas combinações de espaço-tempo, tornando o mundo, em realidade e em experiência, mais interconectado". Ao explanar sobre o deslocamento das identidades culturais nacionais, declara que deste resultam características temporais e espaciais, como a compressão de distâncias e de escalas temporais. Assim, embora com um atraso temporal de meio século, o ideário modernista transforma a realidade local de Irati interconectando-a a esfera global.

Uma das características primordiais da globalização, a compressão espaço-tempo, acelera os processos globais, proporcionando a sensação de que o mundo ficou menor, as distâncias mais curtas e os eventos ocorridos em um determinado lugar têm um impacto imediato sobre pessoas e lugares situados a uma grande distância física (HALL, 2006, p. 69). Nesta mesma linha de pensamento, Giddens (2005, p. 61) define a globalização como sendo a "intensificação das relações sociais em escala mundial, que ligam localidades distantes de tal maneira que acontecimentos locais são modelados por eventos ocorrendo há muitas milhas de distância e vice-versa". Essa sensação de compressão espaço-tempo, no caso a arquitetura modernista de Irati, é diretamente usufruída apenas por um determinado segmento da sociedade, o dos proprietários destas residências, que representam um pequeno percentual entre os diferentes 'espaços de morar' ali consolidados.

Em meio à discussão da 'homogeneização cultural', fica claro que, ao invés do pensamento global substituir as culturas locais, há uma articulação entre o global e o local. Segundo Haesbaert (2007), o termo 'glocalização' ultrapassa o contexto em que situações locais sofrem interferência do global. Para ele:

Nem simplesmente uma justa ou sobreposição de territorialidades em escalas distintas (o global e o local), nem uma imposição unilateral de eventos que ocorrem em uma escala sobre os de outra (o global sobre o local), a glocalização, [...] indica uma combinação de elementos numa nova dinâmica onde eles não podem mais ser reconhecidos estritamente nem como globais, nem como locais, mas sim como um amálgama qualitativamente distinto - global e local combinados, ao mesmo tempo, como um novo processo (HAESBAERT, 2007, p. 347, grifo do autor).

No processo de combinação entre o global e o local, um exemplo ilustrativo são as adaptações realizadas no ideário modernista na escala local. Este é o caso do uso de materiais construtivos regionais, como as pedras ornamentais, em detalhes arquitetônicos nas residências.

Seguindo tal análise, a globalização e a localização acabam por produzir espaços híbridos, sítios glocais, em que diferenciação e integração são 
O "espaço de morar" na arquitetura moderna: reflexões a partir de quatro residências de Irati - PR

Gigliese Aparecida Mendes Cicilian Luiza Löwen Sahr

simultâneos. Assim, o local e o global, deixam de ser entidades fixas, sendo produzidas de forma constante e nunca completas. Dessa forma, deixa-se de lado a distinção entre as formas globais e locais e enfatizamse as suas combinações variadas. O 'global' acaba sendo visto como o "resultado da globalização de condições que previamente eram tidas como "locais" ou "regionais" (HAESBAERT, 2007, p. 347).

Robertson (2000, p. 251) define o termo "glocal" como "um olhar global adaptado às condições locais". Revela ainda o falso antagonismo entre as duas escalas "o global não é em si e por si contraposto ao local. Ao contrário, aquilo que geralmente se entende por local está geralmente no contexto do global" (2000, p. 260). Pode-se dizer, assim, que a globalização, nada mais é que a conexão das diferentes localidades. É neste viés, que o global e o local se combinam, não sendo possível reconhecer um processo separado do outro.Esta combinação pode ser observada através da análise do Movimento Modernista.

No início do século XX surge um movimento que confronta as premissas que eram utilizadas na arquitetura até aquele momento. Em contraste à arquitetura pomposa dos séculos anteriores, nasce uma arquitetura racional, que une técnica e arte. Benevolo (2009, p. 618), ao falar da arquitetura modernista diz que esta "faz desaparecer a diversidade entre o método objetivo do trabalho científico e o método subjetivo do trabalho artístico" e que "a arte e a técnica são indivisíveis, e a invenção plástica pura anda sempre de acordo com as exigências práticas, porque ambas são questões de equilíbrio".

Le Corbusier (2004, p. 29) denomina de 'Revolução Arquitetônica' o final do século XIX, momento em que houve essa mudança no aspecto construtivo. Rompe-se uma linha evolutiva milenar vinda desde a antigüidade mediterrânea e perpassando toda a idade média, onde as técnicas eram constantes: pedra, tijolos e madeira. A partir de então "deixam de sê-lo com o aço perfilado, com o vidro e o concreto armado e os métodos científicos de cálculo de resistência apoiado, tanto quanto possível, na segurança de materiais artificiais de qualidade constante: aços e ligas".

Zevi (1996, p. 121) indica a planta livre como a grande conquista desta nova arquitetura que passa a ser conhecida como arquitetura moderna. As casas agora, já não são cubículos justapostos e isso se deve à "nova técnica construtiva do aço e do concreto, que permite concentrar os elementos de resistência estática num finíssimo esqueleto estrutural".

Há também uma maior mobilidade nas partes internas, onde as divisões são cada vez mais finas e podem curva-se e mover-se livremente, possibilitando a conjugação de ambientes:

Na casa média, a sala de visitas funde-se com a sala de jantar e o escritório, o vestibulo reduz-se, em beneficio da grande sala de estar, o quarto de dormir torna-se menor, os serviços especializam-se, sempre visando conceder maior amplitude a esse grande ambiente articulado onde a família vive, o living room (ZEVI, 1996, p. 123).

Além da mudança na concepção construtiva, Le Corbusier (2004, p. 35) aponta outras: a) a separação entre funções portantes - vigas e pilares e funções portadas - paredes e divisões internas; $b$ ) a fachada servirá apenas para separar o interior do exterior, perdendo a função de portante; c) a estrutura (fundação) independente do imóvel, dando um poder maior de circulação; d) os telhados de concreto armado e a planta livre; e e) a arquitetura é vista como uma arte plástica. Assim "o concreto armado, o ferro e o vidro encontraram, então, as bases fundamentais de sua estética".

Choay (1992, p. 185), ao discutir sobre a revolução arquitetônica modernista e a introdução de novos materiais construtivos como o vidro, o aço e o cimento armado, declara que foram finalmente encontradas as soluções necessárias para construir. Faz alusão também a práticas utilizadas milenarmente como fundações maciças, muros espessos, a escassez de janelas, solos obstruídos por porões, telhados inclinados que eram inutilizáveis e a repetição de disposições iguais de andar em andar, as quais foram substituídas por "uma nova técnica: fundações localizadas, supressão dos muros de arrimo, possibilidade de dispor de toda a fachada para a iluminação, solo livre entre as estreitas estacas, telhados que constituem um solo novo para o uso dos habitantes". 
Rego (2003), ao falar sobre o ideário modernista que Le Corbusier difundia, vai denotar a arquitetura funcionalista pura, em que os cinco princípios modernistas criados por ele - planta livre, fachada livre, janelas em fita, uso de pilotis e o terraçojardim - vão aliar-se à ausência de ornamento aplicado. Além disso, entre seus princípios estéticos estavam o volume e o espaço, substituindo a massa e a solidez; a regularidade no lugar da simetria axial e a exposição de materiais, ao invés do ornamento aplicado.

Entre os profissionais que se destacam nesta nova concepção construtiva, pode-se elencar o estado unidense Frank Lioyd Wright, o francês Le Corbusier e os alemãos Ludwig Mies van der Rohe e Walter Gropius, este influenciado diretamente por Wright. No contexto nacional, o movimento chega mais tarde. Seus efeitos são percebidos a partir da década de 1930 com a construção do prédio do Ministério da Educação e Saúde, MES - no Rio de Janeiro, entre 1937 e 1943. Projeto inovador, desenvolvido por Le Corbusier, juntamente com um grupo composto por arquitetos brasileiros como Lucio Costa, Oscar Niemeyer, Carlos Leão, Moreira, Reidy, entre outros (MIGLIORINI, 2008, p. 60).

Antecedendo a construção do MES, o arquiteto russo Gregori Warchavchik constrói a sua casa em São Paulo, em 1927, sendo esta apontada por muitos como a primeira edificação modernista no Brasil. No entanto, a construção não foi bem aceita no âmbito nacional. Veríssimo e Bittar (1999, p. 38) declaram que "os partidos mais ortodoxos de Warchavchik assustam o público, tendendo a forçar pelo seu aspecto 'atual' a modernização dos espaços habitacionais".

No entanto, a partir da década seguinte, a construção do MES afirmou os ideais modernistas e, nos anos posteriores, vários projetos auxiliaram na consolidação do movimento no país. Aos poucos, a construção 'geometrizada', que abusa do concreto e do aço, das linhas puras e telhados planos, que não dispensa o uso dos brise soleil, das paredes de vidros, das janelas em fitas e dos pilotis ganha a simpatia dos habitantes das cidades de médio e pequeno porte.

É nesse contexto que, na década de 1950 , surgem os primeiros projetos residenciais modernistas na cidade de Irati - PR. Nesta década a cidade vai presenciar várias transformações na sua estrutura urbana. Com o desenvolvimento de novas relações comerciais e financeiras decorrentes da modernização da produção agrícola, a cidade acabou por absorver o excedente de população que estava sem emprego no campo. Desta forma, se até então a cidade de Irati era o "apêndice do campo" (MENDES, 2005, p. 64), agora passa a comandar o espaço produtivo, "havendo um processo de simbiose, em que a cidade e o campo se sustentam, porém com a sobreposição daquela sobre este".

Devido a tais transformações, que culminaram com o crescimento desordenado da cidade e o aumento da sua população, o poder público municipal de Irati vislumbrou a necessidade de formular um planejamento urbano:

Regido por intelectuais vindos de outras cidades, buscou, desde o início, conferir à cidade um caráter funcional. Essa tendência urbanista trazida à Irati, a qual almejava dotar a cidade de racionalidade, tentando transformá-la em "ideal", deve-se ao fato de que os engenheiros, arquitetos e urbanistas recém chegados, traziam consigo forte influência das reformas modernistas ocorridas no inicio do século $X X$ em cidades brasileiras, como por exemplo no Rio de Janeiro. Da mesma forma que ocorreu na capital carioca, em Irati, a intervenção no espaço urbano visou a higienização da cidade, através da modernização de sua infra-estrutura e o embelezamento de suas áreas. (MENDES, 2005, p. 64).

Entre os profissionais descritos na citação anterior, merece destaque o desenhista Eduardo Posfaldo, o qual assumiu o papel de protagonista na difusão da arquitetura moderna a partir da década de 1950 na cidade de Irati.

\section{AS INSPIRAÇÕES LECORBUSIANAS DE EDU- ARDO POSFALDO}

A arquitetura modernista de Irati centra-se, sobretudo, na criatividade do projetista Eduardo Posfaldo (POSFALDO, 2011). Posfaldo nasceu em Irati 
O "espaço de morar" na arquitetura moderna: reflexões a partir de quatro residências de Irati - PR

Gigliese Aparecida Mendes Cicilian Luiza Löwen Sahr

em 21 de setembro de 1935, onde se formou no ensino médio profissionalizante na área contábil. Trabalhou no escritório de engenharia de José Jacob Wasilewski, hoje Rua da Liberdade. Ele criava e acompanhava a execução de projetos arquitetônicos, mesmo sem possuir formação na área de engenharia civil ou arquitetura, havendo a necessidade de um profissional diplomado assinar suas criações.

Casou-se com Leoni Leandro Posfaldo em 1962, na cidade de Irati. Nesta época já morava em Curitiba por motivos profissionais, pois havia sido convidado a trabalhar na Construtora Marna e no Palácio Iguaçu, no departamento de Arquitetura, durante o mandato do governador Ney Braga. Esta construtora era especializada em grandes construções, especialmente igrejas. Posfaldo não trabalhava como um funcionário que cumpria horário, ele desenvolvia seus projetos em sua casa. Segundo relatos de sua esposa, tal construtora desenvolvia projetos inclusive para o Oriente Médio, dada a qualidade de seus trabalhos.

Com o passar do tempo, Posfaldo não trabalhou mais para empresas, vivendo como profissional autônomo, tendo um escritório na sua residência, situada no bairro Batel (Curitiba - Paraná). Pessoas de diversos pontos do Paraná e de Santa Catarina o procuravam para projetar, além de grandes construtoras. Suas obras estão espalhadas pela região centro-sul e centro-oeste do Paraná e pelo litoral paranaense e catarinense, como por exemplo Caiobá e praias particulares situadas ao norte da Praia de Leste no Paraná, e Camburiú em Santa Catarina. Segundo exposição de sua esposa, enquanto as obras eram realizadas, ele as visitava, a pedido dos proprietários, no sentido de verificar se tudo estava saindo conforme seu projeto.

Eduardo Posfaldo detinha um extremo talento e um amplo conhecimento na área arquitetônica, no entanto, não trabalhava com projetos hidráulicos e elétricos das construções, se detendo aos aspectos arquitetônicos. Mesmo em fases mais atuais, que já permitiam o trabalho de desenho arquitetônico com softwares, Posfaldo continuou elaborando seus projetos à mão. Para que o projeto fosse passado para o programa auto-cad, ele contratava estudantes de arquitetura. Segundo Leoni, Posfaldo sempre argumentava que "para desenhar ele apenas precisava de lápis e papel”.

Posfaldo elaborava seus projetos de forma personalizada, levando em conta o histórico econômico, social e até mesmo cultural de cada cliente. Sugeria alguns traçados das tendências que estavam em voga, mas não impunha nada. Dessa forma, cada residência possuía uma característica singular, pois se pensava na construção como algo diretamente relacionado com o indivíduo.

Ele nunca se interessou em ingressar em uma universidade, pois tinha facilidade em conseguir clientes. Muitos eram os engenheiros que iam até ele para tirar dúvidas ou solicitar algumas opiniões, dado o seu conhecimento. Não se importava em não poder assinar seus projetos, por não ter a formação na área. $\mathrm{O}$ que the interessava era satisfazer os clientes, e não necessariamente divulgar seu nome. Nesse sentido, participava de muitos eventos, com trabalhos, mas na maioria dos casos, os trabalhos não eram assinados por ele. Pessoas solicitavam projetos direcionados a exposições, os quais ele elaborava, cobrava por eles, mas não colocava sua assinatura.

Apesar de ter origem humilde, Eduardo Posfaldo era extremamente educado e de gosto refinado. Em relação aos materiais que utilizava, era extremamente exigente: o papel tinha que ser de origem alemã, vindo de São Paulo, e o grafite também era importado. O projetista era detalhista e preocupado com a qualidade de seu trabalho. Nesse sentido, exigia muito dos estudantes de arquitetura que trabalhavam para ele (POSFALDO, 2011).

O conhecimento de Posfaldo não vinha da academia, mas de seu dom e dos contatos que tinha com outros profissionais. Seu gosto pela arquitetura modernista provinha do contato com engenheiros e arquitetos que se inclinavam para essa tendência, pois trabalhou no Palácio do Iguaçu na época em que tal movimento estava no auge e neste local conheceu pessoas provenientes dos mais diversos lugares.

Segundo sua esposa, ele possuía em sua biblioteca particular muitas obras relacionadas aos arquitetos modernistas Le Corbusier e Oscar Niemeyer e sobre o urbanista Lúcio Costa. Sua preferência era 
por profissionais franceses, em especial, Le Corbusier, sabendo detectar nas construções os princípios utilizados pelo arquiteto modernista francês.

Mesmo tendo saído de Irati na década de 1960, diversos componentes da elite da cidade continuaram a procurar pelo seu trabalho. São significativos os exemplares de arquitetura modernista projetados por Posfaldo no espaço urbano de Irati entre as décadas de 1950 e 1970. Isto se deve ao estilo modernista que adotara, o qual era mesclado às singularidades locais.

Seus clientes iratienses pertenciam, na maioria, a famílias tradicionais abastadas. Tais famílias estavam sempre em busca de novidades, e a arquitetura modernista era o novo estilo, sinônimo de status social. Investir no estilo modernista, racional, era estar aberto ao progresso e à procura de expressão de uma identidade própria.

Posfaldo elaborou vários projetos arquitetônicos na cidade de Irati, tanto residenciais como edificações de serviços e entretenimento, como por exemplo o Colégio São Pedro Canísio; S/A Moageira e Agrícola; Igreja Imaculado Coração de Maria; Samuara Clube de Campo; SBCI - Sociedade Beneficente Cultural Iratiense; e a base da Estátua da Santa Nossa Senhora das Graças. Assim, sua obra não se restringiu a vertente modernista.

Trabalhou até a semana que antecedeu seu falecimento. Seu último projeto foi para um médico que construiu no Batel. $\mathrm{O}$ mesmo foi finalizado em software por uma estudante de arquitetura que trabalhava para ele, sendo entregue aos proprietários após sua morte. Eduardo Posfaldo faleceu em julho de 2008, aos 72 anos, em Curitiba - PR, acometido de uma infecção no intestino.

Em meio a várias construções modernistas projetadas por Posfaldo em Irati, estuda-se a seguir 4 residências unifamiliares construídas na década de 1950, as quais pertencem às famílias Zacarias, Zanetti, Grechinski e Pavia e são fortemente marcadas em sua estrutura pela influência modernista.

\section{O "ESPAÇO DE MORAR": REFLEXÕES A PARTIR DE QUATRO RESIDÊNCIAS POSFAL- DIANAS}

Eduardo Posfaldo projetou várias construções na cidade de Irati entre as décadas de 1950 a 1970, onde, em meio a edificações religiosas, de serviços e entretenimento, a maioria eram edificações residenciais. Dentre as criações de Posfaldo, selecionou-se quatro residências unifamiliares modernistas (Figuras 01, 02, 03 e 04), projetadas na década de 1950.

A residência da família Zacarias (Figura 01), considerada de médio porte, é marcada por elementos arquitetônicos modernistas. Possui recuo frontal, nos fundos e na lateral esquerda, entretanto, é colada à divisa lateral direita. Observam-se pans de verr em sua fachada e duas janelas em fita, sendo uma na fachada frontal e outra na lateral. Complementando a fachada frontal, está presente uma marquise em forma de ameba, suportada por finos pilotis de ferro. O telhado inclinado é escondido parcialmente por uma platibanda localizada no centro da construção, com detalhes de seis círculos em relevo negativo. O muro tem a função de segurar a terra do jardim, permitindo ao transeunte a visualização das fachadas frontal e lateral. Esta edificação se mantém até os dias de hoje na função residencial, todavia, atualmente sob posse da família Koch. A fachada não teve alteração alguma se comparada com seu projeto original, permanecendo com as mesmas características de quando foi construída. 


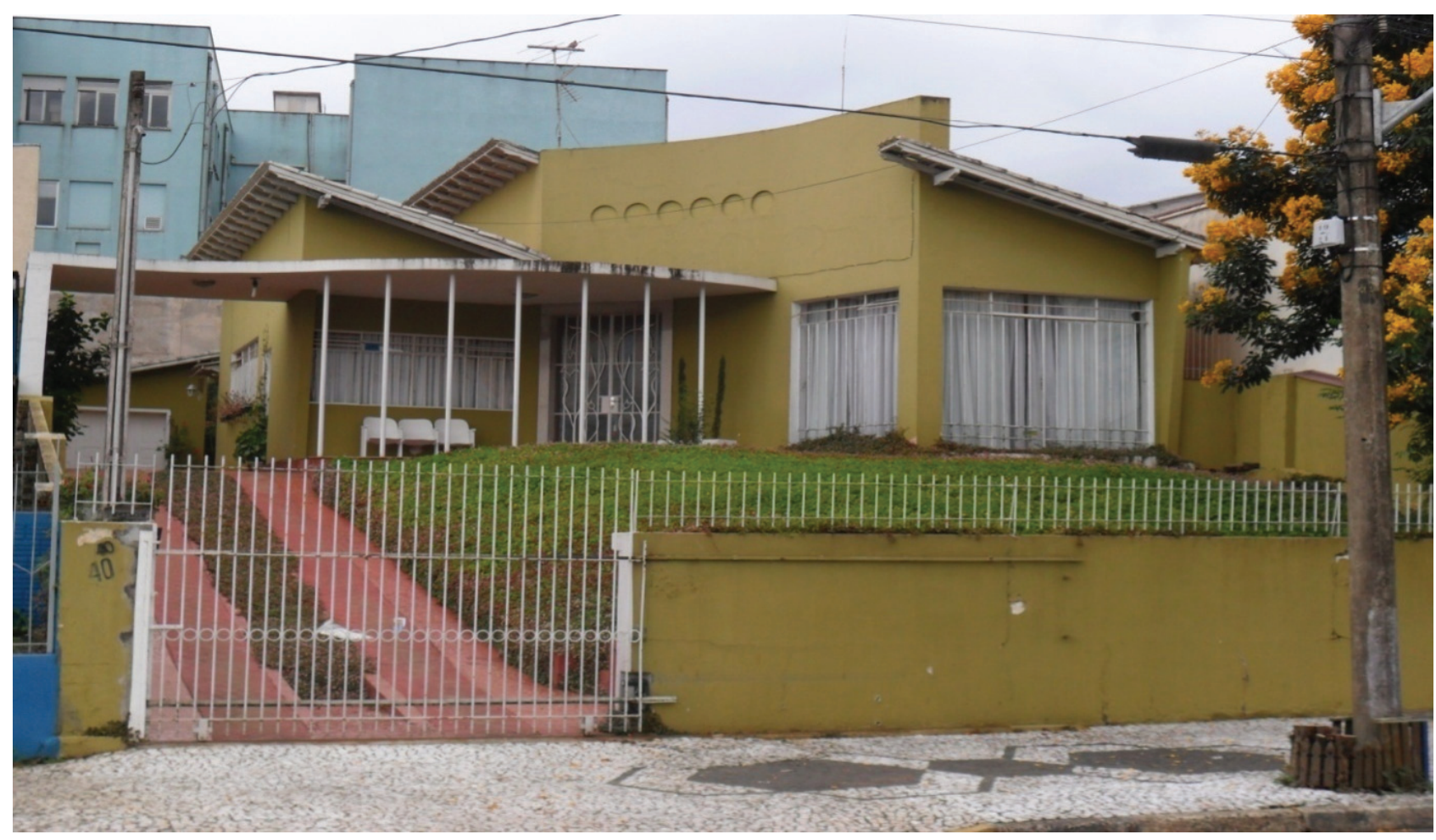

Fonte: Acervo de Mendes, abril de 2011.

A residência foi projetada a pedido de Naby Zacarias (KOCH, 2012), primeiro proprietário, o qual exercia a profissão de médico na cidade. Morou nesta apenas com sua esposa, Inês Sandre, a qual exercia atividade de costureira na própria residência. $\mathrm{O}$ casal não teve filhos e mudou-se para a capital paranaense no final da década de 1950 por motivos profissionais.

A residência da família Zanetti (Figura 02), também considerada de médio porte, encontra-se solta no lote, com recuos frontais, laterais e de fundo. Possui telhado em três folhas, uma com inclinação para frente associada à outra para os fundos, e uma independente com inclinação lateral. A chaminé da lareira, revestida em pedras ornamentais, marca uma linha horizontal na fachada, dividindo-a em duas partes. A fachada, com linhas puras e retas, é evidenciada por pans de verr. Uma marquise de linhas retas cobre o hall de entrada, sendo sustentada por finíssimos pilotis de ferro. O muro frontal baixo permite a visualização de toda a fachada frontal pelo transeunte. Esta edificação se mantém na sua forma, todavia, mudou sua função, abrigando atualmente uma empresa do ramo contábil. Comparando a fachada atual com projeto original, percebe-se ela não foi modificada, permanecendo com suas características originais.

Aresidência foi projetada a pedido de Ildefonso Zanetti, seu primeiro proprietário, o qual exercia a profissão de médico e foi prefeito da cidade no período de 1964 a 1969 (KOMINSKI, 2012). Morou na residência com sua esposa, a dona de casa Dulce Zanetti e seus quatro filhos: Ildefonso Zanetti Filho, Ernesto Zanetti Neto, Fernando Zanetti e Heloisa Zanetti, na época, todos crianças. Segundo relatos (ORREDA, 


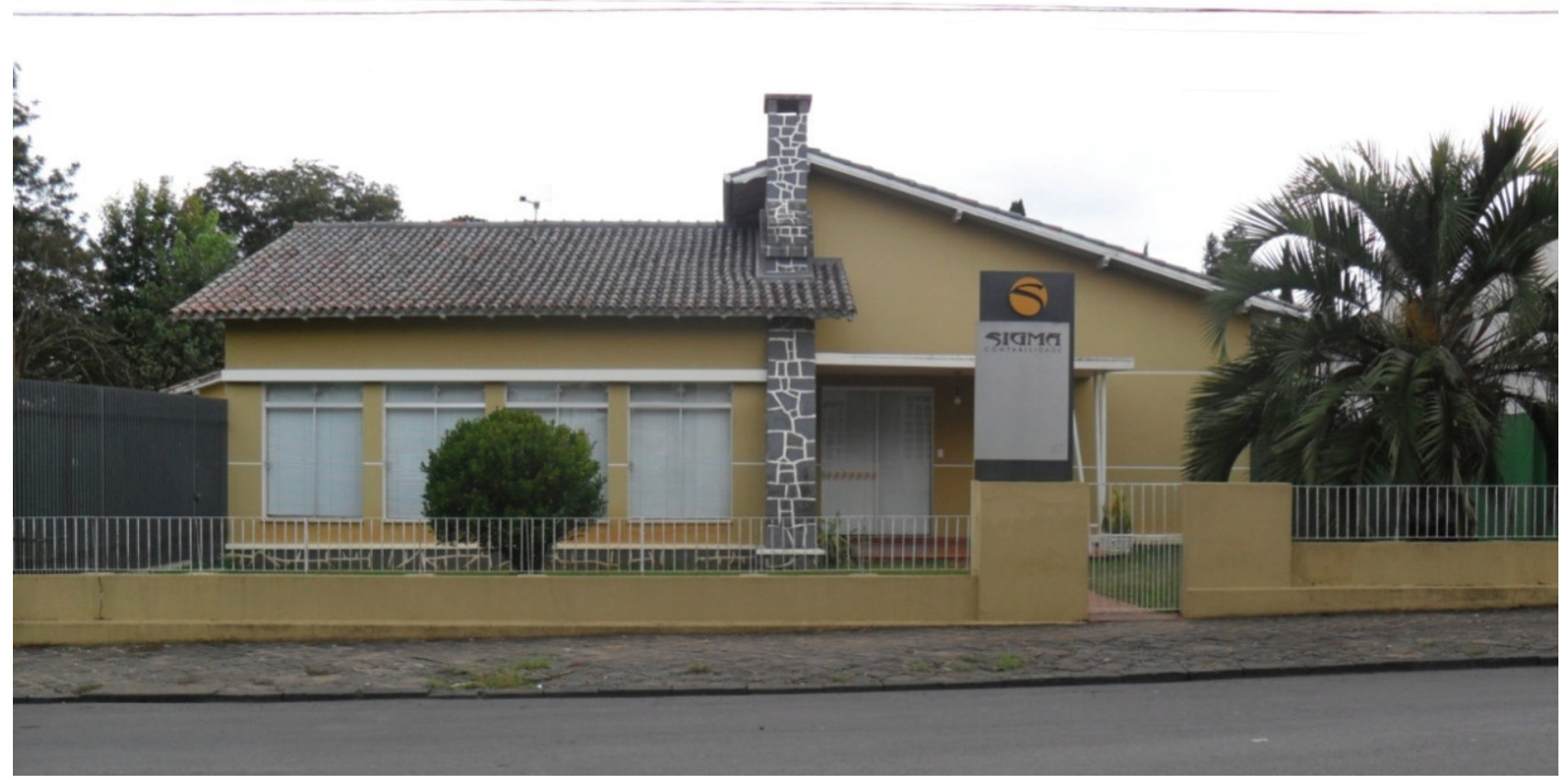

Fonte: Acervo de Mendes, abril de 2011.

2012), em seu mandato foram realizadas várias obras como a construção da rodoviária, ginásio de esportes, 07 escolas rurais e 33 escolas na zona urbana, além da revitalização das existentes. Após terminado seu mandato, voltou a exercer sua profissão como médico. Morou em Irati, na residência modernista, até sua morte na década de 1980.

A residência Grechinski (Figura 03), também considerada uma construção de médio porte, possui recuo frontal, de fundo e na lateral direita, entretanto, é colada à divisa lateral esquerda. Em sua fachada estão presentes elementos como pans de verr e brise soleil, estes para filtrar a iluminação. $O$ telhado não aparente esconde-se em uma platibanda de linhas puras e retas em relevo. As grades altas no muro frontal e nas janelas são elementos posteriores, que se destoam dos ideais modernistas. Originalmente o muro exercia apenas a função de contenção do jardim, permitindo a fruição da fachada por parte dos transeuntes. Até hoje, mantém-se a edificação na sua função residencial sob posse da mesma família. A fachada original sofreu algumas alterações quando comparada com a atual.
Além das grades nas janelas, as quais foram colocadas em uma reforma recente, ao invés da janela do meio, no projeto original havia um detalhe na parede com cobogós. Havia também uma rampa de acesso até a porta, fazendo com que o jardim ficasse em um plano abaixo da construção. No entanto, mesmo com a reforma, a residência continua com suas características modernistas, onde as linhas retas e puras dão o acabamento da obra.

A residência foi projetada a pedido de Miguel Luciano Grechenski, seu primeiro proprietário, o qual era empresário da cidade, sócio da cerealista Apiaba (GRECHINSKI, 2012). Miguel Luciano Grechinski, juntamente com a sua família: a esposa e dona de casa Ester Grechinski e mais três filhos, na época crianças, Roseli Grechinski, João Grechinski e Miguel Grechinski Filho; moraram na referida residência um período menor que um ano. Por motivos profissionais, Miguel, juntamente com a família, mudou-se para o Rio de Janeiro, ficando a residência fechada.

Após sete anos, a residência, que vinha deteriorando-se, foi novamente habitada, agora por Casimiro Grechinski, que a comprou de seu irmão. Quando 
O "espaço de morar" na arquitetura moderna: reflexões a partir de quatro residências de Irati - PR Gigliese Aparecida Mendes Cicilian Luiza Löwen Sahr

Figura 03: Residência em estilo modernista projetada para a Família Grechinski

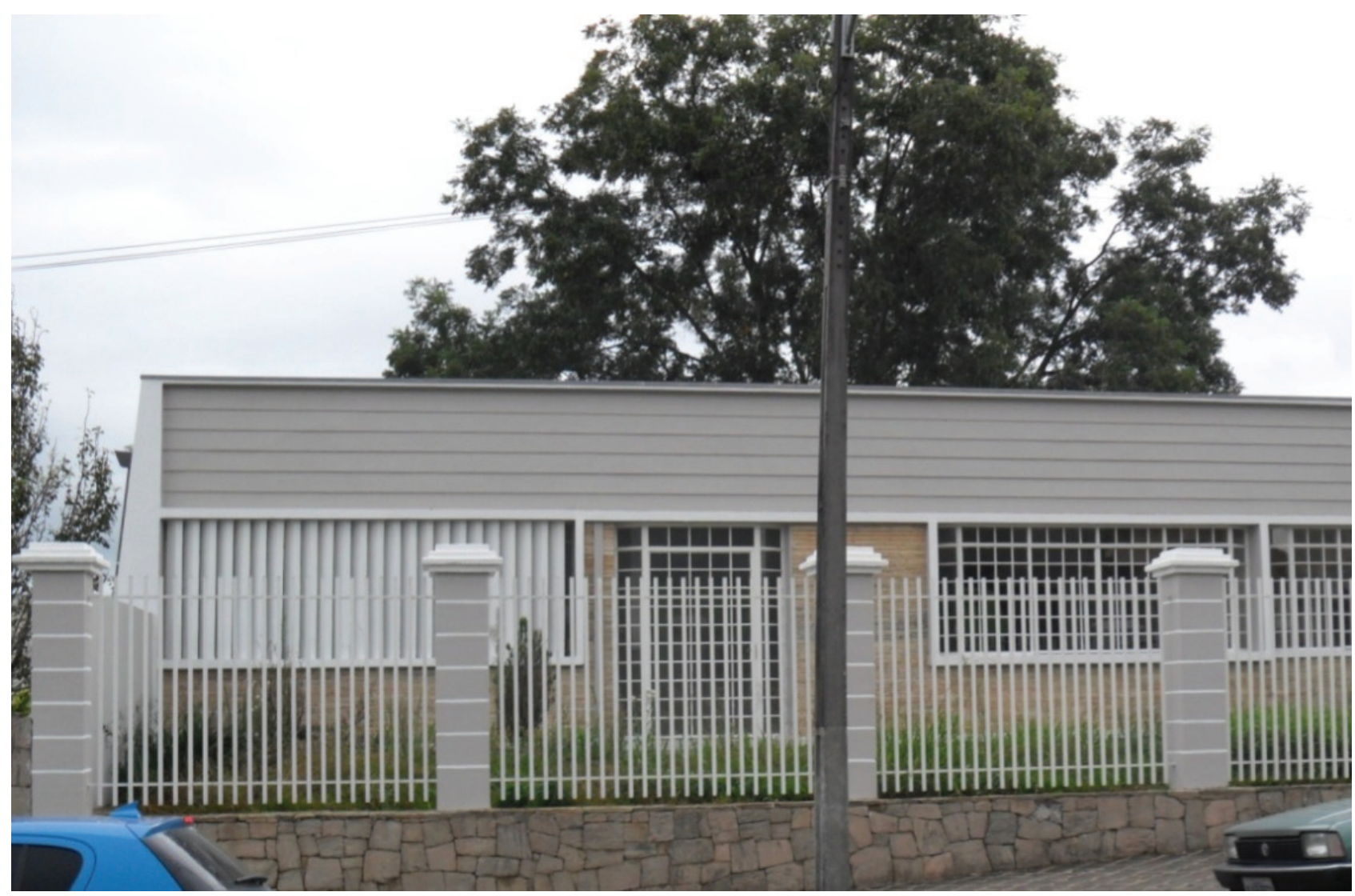

Fonte: Acervo de Mendes, abril de 2011.

mudou-se para a residência, o casal Casimiro Grechinski e sua esposa, a dona de casa Terezinha Grechinski, tinha apenas um filho, o recém nascido Davi. Ao longo dos anos, eles tiveram mais quatro filhos, sendo: Daniel Grechinski, Débora Natasha Grechinski e Andréia Grechinski. Até hoje o casal mora na cidade de Irati, todavia, sua residência modernista encontra-se alugada (GRECHINSKI, 2012).

A residência da família Pavia (Figura 04), considerada de grande porte, encontra-se solta no lote, com recuos laterais, frontal e de fundo. Sua fachada é marcada por dois grandes pans de verr. O telhado em asa de borboleta é coberto por grandes platibandas ornamentais que compõe figuras geométricas, associadas a uma laje, situada ao meio e revestida por pedras ornamentais. O muro tem a função de contenção da terra do jardim, sendo a grade superior elemento posterior. Ao transeunte é permitida a visualização da fachada como um todo. A edificação mantém sua função residencial, no entanto, atualmente sob a posse da família Kominski. Comparando a fachada atual com o projeto original, nota-se que esta continua com as características de quando foi construída, não alterando seus elementos modernistas.

A residência foi projetada a pedido de Arrigo Pavia, proprietário da Carvorite, empresa produtora de carvão. Imigrante italiano, após morar certo tempo em São Paulo, mudou-se para Apiaba, localidade rural do município de Irati. Somente no final da década de 1950 é que Arrigo mudou-se para a cidade, construindo a residência em que morou com a esposa, a dona de casa Aceli Prado Pavia, e sua primeira filha, Ida Pavia. O casal ainda teve mais três filhos, que nasceram e viveram na residência. Segundo relatos (KOCH, 2012), a família morou na cidade aproximadamente oito anos, mudando-se posteriormente para Curitiba, por motivos profissionais. 
Figura 04: Residência em estilo modernista projetada para a Família Pavia

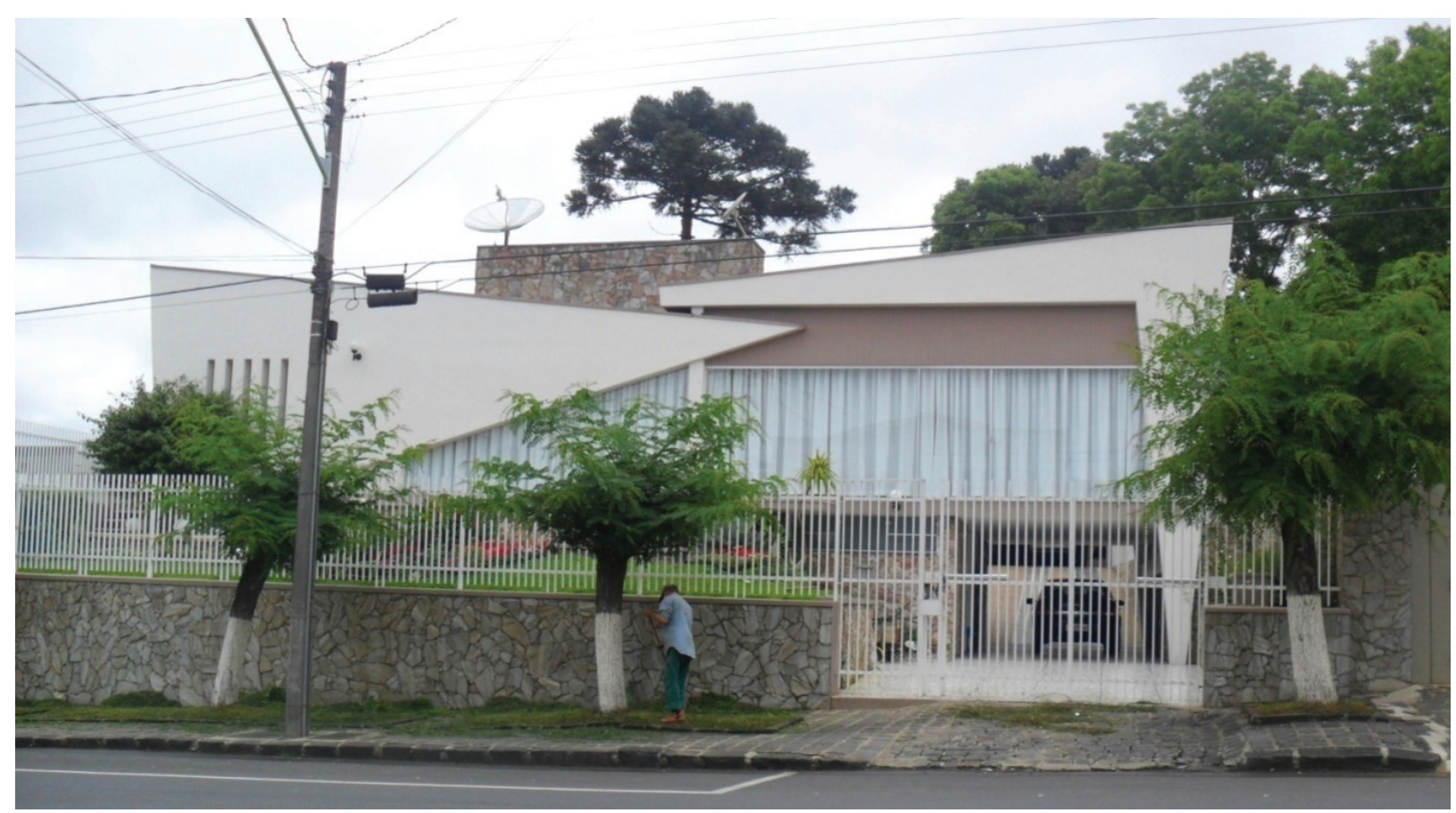

Fonte: Acervo de Mendes, novembro de 2011.

Observando-se as quatro residências, elementos modernistas como pans de verr, pilotis, platibandas, marquises e linhas retas se fazem presentes alternadamente em todos os casos. Quanto às linhas, nota-se que apenas a residência da família Zacarias é que se utiliza de curvilíneas, no caso da marquise em forma de ameba, nas demais a preferência é pelas linhas retas. Além disso, o elemento brise soleil aparece apenas na residência Grechinski, e o telhado não aparente é encontrado tanto na residência Grechinski como na Pavia.

Para fins de análise destas residências en- quanto espaços de morar são apresentados, a seguir, informações retiradas dos projetos originais das casas, projetos estes disponíveis no acervo do Departamento de Controle Interno de Documentos da Prefeitura Municipal de Irati. Com relação ao porte das residências escolhidas (Tabela 01), observa-se que três delas não ultrapassando $220 \mathrm{~m}^{2}$, podendo ser consideradas de médio porte. Trata-se das residências projetadas originalmente para as famílias Zacarias, Zanetti e Grechinski. A residência projetada originalmente para a família Pavia é considerada de grande porte, ultrapassando $350 \mathrm{~m}^{2}$.

Tabela 01 - Residências modernistas de Irati, segundo a família original, o ano de construção, a área construída, a área do lote e a taxa de ocupação - Projetos de Posfaldo da década de 1950

\begin{tabular}{|l|c|c|c|c|}
\hline Família Original & Ano de Construção & $\begin{array}{c}\text { Área Construída } \\
\left(\mathrm{m}^{2}\right)\end{array}$ & $\begin{array}{c}\text { Área do Lote } \\
\left(\mathrm{m}^{2}\right)\end{array}$ & $\begin{array}{c}\text { Taxa de Ocupação } \\
(\%)\end{array}$ \\
\hline Zacarias & 1953 & 206,10 & 580 & 35,53 \\
\hline Zanetti & 1955 & 206,92 & 1029,80 & 20,09 \\
\hline Grechinski & 1958 & 219,23 & 630 & 34,8 \\
\hline Pavia & 1958 & 360,35 & 1070 & 33,7 \\
\hline Média & --- & 248,15 & 827,45 & 31,03 \\
\hline
\end{tabular}

Fonte: Plantas do DCID da PMI. Org.: Mendes, 2011. 
O "espaço de morar" na arquitetura moderna: reflexões a partir de quatro residências de Irati - PR

Gigliese Aparecida Mendes Cicilian Luiza Löwen Sahr

Quanto à taxa de ocupação, percebe-se que nos quatro casos esta não ultrapassa os $40 \%$ do lote. A maior taxa é a da residência Zacarias com $35,53 \%$ e a menor é a da Zanetti com 20,09\%. Analisando tais dados, conclui-se que todas as residências têm lotes de grandes dimensões, no entanto, em dois casos, estas são coladas nas divisas laterais, como é o caso das residências Zacarias e Grechinski, ou seja, nas casas de médio porte. Embora os ideais modernistas indiquem a planta livre, ou seja, totalmente descolada das dividas do lote, o que nem sempre ocorre em Irati, infere-se que se mantêm a premissa de grandes espaços verdes e de jardins em todos os casos estudados.

Buscando aprofundar a análise dos espaços de morar nas residências modernistas de Irati, adequou-se a classificação de Veríssimo e Bittar (1999). Segundo estes autores, os espaços internos das residências se classificam em: social, íntimo e de serviços. Para fins deste estudo, optou-se por cinco classes de 'espaço de morar':

a) Espaço social - espaço tratado com formalidade, servindo como transição entre o exterior e o interior. Apropriado para recepção das visitas, devendo apresentar-se sempre organizado e com requinte, passando a ideia do status social da família. Representado pelo hall social, sala de estar, sala de jantar (copa na inexistência da sala de jantar), banheiro social e terraço social. b) Espaço íntimo - espaço reservado aos integrantes da família, com acesso restrito. Representado por quartos de dormir e banheiros íntimos.

c) Espaço de serviço - espaço reservado para a realização das tarefas que movimentam a casa e que são utilizados, sobretudo, por empregados domésticos. Representado pela cozinha, área de serviços, quarto de empregada, sala de costura e depósitos.

d) Espaço profissional - espaço destinado ao trabalho profissional específico de um ou mais integrantes da família, no qual se recebe (ou não) clientes/pacientes. Representado por escritório, consultório, sala de espera e sala de leituras.

e) Espaço de circulação - área destinada à circulação dos habitantes da casa. Representada por corredores, escadas e garagens que interligam os demais espaços.

Quanto à divisão dos 'espaços de morar' nas residências modernistas de Irati (Tabela 02), este segue um mesmo padrão, onde o espaço íntimo detém a maior área construída, seguida do espaço social. $\mathrm{O}$ espaço social é privilegiado nas residências Zanetti e Pavia. No caso da residência Zanetti também o espaço íntimo apresenta destaque em relação à média das 4 residências analisadas. Na residência Grechinski, o destaque é para a área de serviços.

Tabela 02 - 'Espaços de morar' das residências modernistas de Irati, segundo o uso - Projetos de Posfaldo da década de 1950

\begin{tabular}{|c|c|c|c|c|c|c|c|c|c|c|}
\hline \multirow{3}{*}{$\begin{array}{l}\text { Família } \\
\text { Original }\end{array}$} & \multicolumn{10}{|c|}{ Espaços de morar* } \\
\hline & \multicolumn{2}{|c|}{ Social } & \multicolumn{2}{|l|}{ Íntimo } & \multicolumn{2}{|l|}{ Serviços } & \multicolumn{2}{|c|}{ Profissional } & \multicolumn{2}{|c|}{ Circulação } \\
\hline & $\mathrm{m}^{2}$ & $\%$ & $\mathrm{~m}^{2}$ & $\%$ & $\mathrm{~m}^{2}$ & $\%$ & $\mathrm{~m}^{2}$ & $\%$ & $\mathrm{~m}^{2}$ & $\%$ \\
\hline Zacarias & 51,52 & 26,19 & 51,40 & 26,14 & 26,83 & 13,64 & 22,02 & 11,19 & 44,89 & 21,78 \\
\hline Zanetti & 59,10 & 33,63 & 67,19 & 38,23 & 12,07 & 6,87 & --- & ---- & 37,40 & 18,07 \\
\hline Grechinski & 26,90 & 14,43 & 45,90 & 24,64 & 68,46 & 36,73 & ---- & ---- & 45,12 & 20,58 \\
\hline Pavia & 97,15 & 31,15 & 77,95 & 24,99 & 55,45 & 17,78 & 14,88 & 4,77 & 66,44 & 18,43 \\
\hline Média & 58,67 & 26,35 & 60,61 & 28,50 & 40,70 & 18,76 & 9,23 & 3,99 & 48,46 & 19,71 \\
\hline
\end{tabular}

Nota: $(*)$ Considerou-se apenas as áreas úteis, ou seja, não foram computadas as áreas das paredes.

\author{
Fonte: Plantas do DCID da PMI
}

Org.: Mendes, 2011. 
O espaço profissional está presente em duas residências. O projeto da residência da família Zacarias é constituído de uma sala de espera e de um consultório, tendo em vista que o primeiro proprietário, Naby Zacarias, atuava como médico. No projeto da residência Pavia encontra-se uma sala de leitura, onde provavelmente Arrigo Pavia trabalhava ou mantinha seu hobby, tendo em vista que ele era um empresário de renome na cidade.

Em uma análise quantitativa dos cômodos e suas funções (Tabela 03), nota-se que, nas residências analisadas, há uma tendência da quantidade de cômodos no espaço de serviços ser maior, seguido pelo espaço íntimo. Isto se repete tanto nas residências de médio como de grande porte. Tal tendência do espaço de serviços possuir maior quantidade de cômodos deve-se ao fato da superposição de funções existentes nestes compartimentos, como a realização das tarefas domésticas: preparar e servir a alimentação, lavar e passar roupas e a manutenção dos empregados. Além disso, há os cômodos destinados a guardar utensílios que não são mantidos nos demais espaços, e a garagem, local onde se mantém o veículo da família. Na década de 1950 se projetava apenas um automóvel por família, diferentemente do que ocorre na atualidade. A residência Zanetti acaba destoando da tendência das demais, tendo em vista que a maior quantidade de cômodos pertence ao espaço íntimo, representado por quatro quartos e um banheiro, ao passo que o espaço de serviços é bem modesto, possuindo apenas dois cômodos: cozinha e copa.

Tabela 03 - Quantidade e tipologia dos cômodos das residências modernistas de Irati, segundo os espaços de morar - Projetos de Posfaldo da década de 1950

\begin{tabular}{|c|c|c|c|c|}
\hline \multirow{2}{*}{$\begin{array}{l}\text { Família } \\
\text { Original }\end{array}$} & \multicolumn{4}{|c|}{ Espaços e morar ( $n^{\circ}$. e tipologia) } \\
\hline & Social & Íntimo & Serviços & Profissional \\
\hline Zacarias & $\begin{array}{l}03 \text { - sala de estar, } \\
\text { sala de jantar (copa) } \\
\text { e banheiro social }\end{array}$ & $\begin{array}{l}04-\text { quartos e } \\
\text { banheiro íntimo }\end{array}$ & $\begin{array}{l}04 \text { - cozinha, área de } \\
\text { serviços, banheiro de } \\
\text { empregada e depósito de } \\
\text { lenha }\end{array}$ & $\begin{array}{l}02 \text { - sala de espera e } \\
\text { consultório }\end{array}$ \\
\hline Zanetti & $\begin{array}{l}03 \text { - sala de estar, } \\
\text { sala de jantar (copa) } \\
\text { e hall }\end{array}$ & $\begin{array}{l}05-\text { quartos e } \\
\text { banheiro }\end{array}$ & 01 - cozinha & ---- \\
\hline Grechinski & $\begin{array}{l}02 \text { - living (Sala de } \\
\text { estar e jantar } \\
\text { conjugadas) }\end{array}$ & $\begin{array}{l}04-\text { quartos e } \\
\text { banheiro }\end{array}$ & $\begin{array}{l}06 \text { - cozinha, copa, } \\
\text { despensa, área de } \\
\text { serviços, banheiro de } \\
\text { empregada e quarto de } \\
\text { despejo }\end{array}$ & ---- \\
\hline Pavia & $\begin{array}{l}05 \text { - sala de visitas, } \\
\text { bar, sala de jantar, } \\
\text { hall de entrada e } \\
\text { terraço social }\end{array}$ & $\begin{array}{l}06 \text { - quartos e } \\
\text { banheiros }\end{array}$ & $\begin{array}{l}08 \text { - cozinha, copa, } \\
\text { dependências de } \\
\text { empregada (quarto e } \\
\text { banheiro), quarto de } \\
\text { costura, área de serviços, } \\
\text { terraço e adega }\end{array}$ & 01 - sala de leitura \\
\hline
\end{tabular}

Fonte: Plantas do DCID da PMI

Org.: Mendes, 2011.

\section{CONSIDERAÇÕES FINAIS}

O modernismo arquitetônico mostra-se bastante presente na cidade de Irati, marcando sua paisagem urbana, principalmente na área central. Esse estilo, tão cotizado na década de 1950, imprime idade uma composição de destaque. Trata-se de edificações que destoam pelas suas linhas puras e retas, aliadas a grandes pans de verr, platibandas em formas geométricas e marquises sustentadas por finíssimos pilotis. Todos estes elementos encontram-se conjugados à concepção racionalista do construir e do morar.

A apropriação dos motivos modernistas assegurou o status almejado pela classe média emergente e pela classe alta já estabelecida na cidade. $\mathrm{O}$ espaço de morar integrou casa e homem, ou seja, 
O "espaço de morar" na arquitetura moderna: reflexões a partir de quatro residências de Irati - PR

Gigliese Aparecida Mendes Cicilian Luiza Löwen Sahr

as residências passaram a ser projetadas para as novas necessidades impostas as famílias modernas. Nota-se que, ao desempenharem funções específicas, as partes internas das residências proporcionaram mobilidade aos moradores, o que resultou na construção de ambientes diferenciados, rompendo a tradição do estilo de morar que era perpassada por uma organização mais convencional. Assim, observou-se uma transformação na unidade compositiva, não sendo apenas um 'modernismo de fachada', como debatido por Lara (2005), onde a planta era muito semelhante aos modelos anteriores.

Baseando-se nas quatro residências desenhadas por Eduardo Posfaldo durante a década de 1950, conclui-se que é seguido um padrão modernista na distribuição dos espaços internos, o qual privilegia os espaços íntimos e sociais. Todavia, a arquitetura modernista iratiense possui suas singularidades. No campo estético da fachada, por exemplo, as linhas curvas foram utilizadas apenas para detalhes construtivos. No espaço de morar, a inserção de espaços profissionais se constituiu em mais uma peculiaridade, pela qual as circunstâncias dos proprietários fizeram com que o movimento global sofresse adaptações, dando-se a entender que o Modernismo, ao se reproduzir e adaptar ao local, possibilitou a criação de uma realidade ímpar no campo arquitetônico e uma identidade própria aos seus moradores.

\section{GLOSSÁRIO}

Brise-soleil - Painéis móveis ou fixos, orientáveis, basculantes, horizontais e verticais, para a proteção ou direcionamento de insolação.

Cobogó - Elemento vazado, pode ser de concreto, cerâmica, alvenaria. Impede que o interior da edificação seja visto de fora. Filtra a luz solar e o vento.

Fachada - Parede frontal da edificação, voltada para a rua.

Janelas em fita -Aberturas sequenciais marcadas pela horizontalidade. Altura da abertura bastante inferior à sua largura.

Marquise - Cobertura que serve de proteção da chuva e sol, sem paredes laterais.

Pan de verr - Panos de vidro, grandes superfícies de vidro.
Piloti ou pilar - Elemento vertical de sustentação da edificação. Integra o sistema estrutural da construção.

Telhado em asa de borboleta- Cobertura com a inclinação voltada para o centro da edificação.

Telhado plano - Cobertura horizontal, sem inclinação.

\section{REFERÊNCIAS}

BENEVOLO, Leonardo. História da Cidade. São Paulo: Editora Perspectiva, 2009.

CHOAY, Françoise. O Urbanismo. 3. ed. São Paulo: Perspectiva, 1992.

GRECHINSKI, Terezinha. Entrevista. Fornecida a Gigliese Mendes. 07 de março de 2012.

GIDDENS, Anthony. Sociologia. 6. Ed. Porto Alegre: Artmed, 2005.

HAESBAERT, Rogério. O Mito da Desterritorialização. Do "Fim dos Territórios" à Multiterritorialidade. 3. ed. Rio de Janeiro: Bertrand Brasil, 2007.

HALL, Stuart. A Identidade Cultural na Pós-Modernidade. 11. ed. Rio de Janeiro: DP\&A, 2006.

KOCH, Adair. Entrevista. Fornecida a Gigliese Mendes. 19 de março de 2012.

KOMINSKI, Amilton. Entrevista fornecida a Gigliese Mendes. 07 de março de 2012.

LARA, Fernando Luiz Camargo. Modernismo Popular: Elogio ou Imitação? Caderno de Arquitetura e Urbanismo, Belo Horizonte, v. 12, n. 13, p. 171184, 2005. Disponível em:<http://www.pucminas. br/imagedb/documento/DOC_DSC_NOME_ARQUI20070514091852.pdf>. Acesso em: 24 out. 2011.

LE CORBUSIER. Planejamento Urbano. São Paulo: Editora Perspectiva S. A., 2004. 
MENDES, Gigliese Aparecida. Segregação Urbana em Irati (1950-1960). 2005. 95 f. Monografia (Especialização em Perspectivas do Ensino de História do Brasil) - Departamento de História, Universidade Estadual do Centro-Oeste, Irati, 2005.

MIGLIORINI, Jeanine Mafra. Pilotis e Pans de Verres sob a ótica Bourdiana: um estudo sobre a arquitetura modernista no espaço urbano de Ponta Grossa - PR. 2008. 179 f. Dissertação (Mestrado em Gestão do Território) - Departamento de Geografia, Universidade Estadual de Ponta Grossa, Ponta Grossa, 2008.

ORREDA, José Maria. Entrevista fornecida a Gigliese Mendes. 12 de março de 2012.

POSFALDO, Leoni Leandro. Entrevista fornecida a Gigliese Mendes. 08 de outubro de 2011.

REGO, Renato Leão. DELMONICO, Renato. Casas de estilo: arquitetura moderna e edificações residenciais em Maringá, Estado do Paraná. Acta Scientiarum. Technology, Maringá, v. 25, n. 2, 2003, p. 179-184.

ROBERTSON, Roland. Globalização. Teoria Social e Cultura Global. Petrópolis: Editora Vozes, 2000.

SANTOS, Milton. O Lugar e o Cotidiano. In: A Natureza do Espaço. Técnica e Tempo, Razão e Emoção. São Paulo, EDUSP: 2009a.

VERÍSSIMO, Francisco Salvador; BITTAR, William Seba Mallmann. 500 anos da Casa no Brasil. 2. ed. Rio de Janeiro: Ediouro, 1999.

WARNIER, Jean Pierre. A Mundialização da Cultura. São Paulo: EDUSC, 2000.

ZEVI, Bruno. Saber ver a Arquitetura. 5. ed. São Paulo: Martins Fontes, 1996. 